\title{
ALGUNS DESCOMPASSOS NO ENSINO DE LITERATURA: DOCUMENTOS E PRÁTICAS OFICIAIS
}

\author{
Mayra Pinto \\ mayrapinto@uol.com.br
}

\section{DESCOMPASSOS}

Quando os Parâmetros Curriculares Nacionais/Ensino Fundamental (PCN) foram divulgados em 1998, a orientação metodológica no ensino de Língua Portuguesa (LP) teve uma guinada importante não só para o estudo do texto de um modo geral, mas também para o ensino de literatura. Uma de suas propostas inovadoras é que haja uma ampla diversidade de gêneros discursivos estudados em sala de aula por meio de uma abordagem enunciativa. Dentre outras, uma das justificativas para esse novo enfoque é bem conhecida: dado o alto número de alunos das classes populares, que entraram para a escola com a democratização da educação desde os anos 8o, privilegia-se o ensino de gêneros que circulam, sobretudo, no uso público formal, de modo a favorecer, no sentido de ampliar, seu universo de letramento. Um dos principais objetivos dessa orientação é incrementar o uso da linguagem em diferentes situações de comunicação para que esses alunos tenham plena participação social. Os textos literários deixam de ser privilegiados no estudo da língua, como era costume no ensino de LP até então, e passam a conviver, portanto, ao lado de textos das esferas jornalística, científica, propagandística, política, etc.

Embora a abordagem dos PCN tenha claramente uma preocupação política, no sentido de que a metodologia de ensino proposta procura levar em consideração uma questão social própria da maioria do alunado 
brasileiro, a não priorização dos textos literários, paradoxalmente, pode contribuir, dentre outros aspectos, para impedir a expansão do universo de letramento de milhões de crianças e jovens brasileiros por várias razões. Uma delas é que ao romper com um tipo de metodologia, cujo enfoque estava no estudo das obras literárias consagradas e na gramática até a década de 70, e com a orientação didática subsequente, que privilegiava o texto como principal unidade de ensino da leitura e da escrita, segundo Regina Zilberman, a abordagem dos PCN acaba por excluir ainda mais o aluno das classes populares de uma tradição cultural: "A dissociação faz com que a literatura permaneça inatingível às camadas populares que tiveram acesso à educação, reproduzindo-se a diferença por outro caminho"; para a autora, até o surgimento dos novos parâmetros "a literatura ficava no fim ou de fora" dos programas curriculares, no entanto, atualmente "não está em parte alguma” (2009, p. 17). A exclusão torna-se mais dramática ainda, se a encararmos sob a perspectiva discursiva de viés bakhtiniano. Nessa abordagem, como se sabe, o texto literário é visto como uma síntese dos valores sociais, importante não só para conhecer esses valores, mas também para refletir sobre eles:

Na literatura são importantes sobretudo os valores subentendidos. Se pode dizer que uma obra artística é um potente condensador de valorações sociais não expressadas: cada palavra está impregnada delas. São justamente essas valorações sociais as que organizam a forma artística enquanto sua expressão imediata. (VOLOCHÍNOV, 2013, p. 88)

Sob essa perspectiva, portanto, a formação do leitor literário implica necessariamente possibilitar o acesso do aluno a uma linguagem que contribui para que ele conheça, além de uma forma artística, a própria conformação axiológica da sociedade em que vive.

No caso dos Parâmetros Curriculares para o Ensino Médio (PCNEM e $\mathrm{PCN}+$ ), publicados em 2000 e 2002 respectivamente, foram produzidos dois documentos que procuravam ajustar sua proposta inicial a uma abordagem mais voltada ao trabalho com a literatura: Orientações curriculares/ literatura (OSAKABE e FREDERICO, 2004) e as Orientações curriculares do ensino médio/Linguagens, códigos e suas tecnologias (BRASIL, 2006). Apesar desse ajuste das Orientações curriculares, a opinião de Zilberman é corroborada por outros pesquisadores que evidenciam como, nessa primeira década, o ensino de literatura no Ensino Médio (EM) ou permaneceu nos limites do ensino tradicional (PAULINO e COSSON, 2009; RANGEL, 2005) - porque trabalha sobretudo com a história literária, os estilos, as épocas, em detrimento da leitura do texto propriamente -, ou tendeu a desaparecer (FISCHER et al., 2012) - nesse caso, o aluno precisa ter estudado muito pouco literatura para passar nos exames do ENEM. 
Ao longo dos anos 2000, essa vertente que problematiza o ensino de literatura em todo o ensino básico brasileiro dialogou comvários documentos oficiais. Alguns exemplos são as já citadas Orientações curriculares (2004 e 2006), o Guia de Livros Didáticos: PNLD 2013 (2012) e o documento, elaborado para o Ministério da Educação, Por uma política de formação de leitores (BERENBLUM e PAIVA, 2006) que indicam não só entraves para o ensino de literatura, bem como uma séria preocupação em superar esse problema, na medida em que os documentos apontam diferentes estratégias para enfrentá-lo. No entanto, essa preocupação parece ainda não ter ecoado em certas práticas institucionais, que interferem diretamente na formação literária do aluno do ensino básico. Ao contrário, pesquisas recentes indicam, pela análise de algumas provas oficiais e livros didáticos (LD) avaliados pelo MEC e consequentemente adquiridos pelo governo federal para serem distribuídos gratuitamente nas escolas -, que o aluno brasileiro pode prescindir da formação literária para completar sua formação geral, de acordo com o material didático que o forma e as avaliações a que se submete (BELINTANE, 2011, FISCHER et al., 2012, RANGEL, 2005).

No momento atual, observa-se, portanto, em relação ao ensino de literatura, uma espécie de descompasso entre o que orientam alguns documentos oficiais e certos critérios de avaliação de determinadas instâncias oficiais, isto é, entre o que se quer enquanto ensino de literatura e o que se exige para a formação do aluno.

No âmbito do EF, em sua tese de livre docência $A$ oralidade faz escrita $n a(s)$ infâncias(s): pesquisas e reflexões sobre a relação oralidade - escrita nos anos iniciais de escolarização (2011), Belintane faz uma compilação de material das avaliações da Prova Brasil, Sistema de Avaliação de Rendimento Escolar do estado de São Paulo (SARESP) e Prova São Paulo, de algumas atividades de manuais didáticos aprovados pelo Programa Nacional do Livro Didático-PNLD/2010 e de duas pesquisas feitas em escolas públicas paulistanas. Ao analisar algumas provas de avaliação, além de constatar que a literatura tem uma presença menor do que textos de outras esferas - no SARESP, "ocupa $20 \%$ do contínuo" -, Belintane demonstra que o tratamento dado ao texto literário - quadrinhos etc. - é bastante superficial, isto é, de um modo geral, estimula-se a leitura direta, "com pouca ênfase nos efeitos de sentido mais produtivos e inteligentes" (2011, p. 121). As questões voltam-se para aferir diversos tipos de habilidades de modo isolado, o que significa, portanto, que poderiam ter como objeto textos de qualquer gênero.

No EM, essa mesma constatação fazem Fischer et al., que pesquisaram as questões referentes à literatura em todas as provas do Exame Nacional do Ensino Médio (ENEM) no período de 1998 a 2010: "Na literatura, está claro que o estudante precisa demonstrar somente a habilidade de 
decodificar textos (nesse sentido, Drummond está na mesma posição de uma placa de ônibus, de uma letra de rap ou de um discurso político)." (2012, p. 120). Ao estabelecer a relação entre o documento, que deveria ser o orientador didático da avaliação, e a prova oficial, os autores lembram que a Matriz de referência do ENEM propõe conteúdos sobre o ensino de literatura não encontrados na avaliação. Segundo eles, as questões de literatura assumem um "caráter figurativo", dado que exigem do aluno apenas "a interpretação direta de um texto, geralmente um poema; nada de relações históricas, entre autores ou períodos literários, de contextos estéticos, de traços de teoria literária, enfim, dos conteúdos arrolados na Matriz de Referência do exame." (2012, p. 118).

Infelizmente, em alguns aspectos, a distância entre orientações didáticas e práticas institucionais atinge até mesmo o ensino de língua - campo em que a abordagem linguística vem se ampliando de modo bem sucedido - quando ele toca, de alguma forma, o campo literário. Por exemplo, uma competência bastante destacada atualmente diz respeito ao conhecimento da variação linguística. Nas questões analisadas por Belintane, mais especificamente na Prova Brasil, tratase dessa competência com a orientação de respeitar uma fala de "alunos considerados linguisticamente fora do processo de ensino/aprendizagem" (PDE - Prova Brasil - matrizes de referência, temas, tópicos e descritores /Ensino Fundamental 2008/2009, p. 104 apud BELINTANE, 2011, p. 114). Essa preocupação, por mais bem fundamentada que esteja politicamente, acaba gerando testes com um tratamento artificial das inúmeras variações, o que impede a reflexão do "essencial: que as normas regionais rendem literatura tanto quanto a tal norma culta” (BELINTANE, 2011, P. 114). Isto é, na produção cultural regional, há uma reflexão sobre os mais diversos temas, há uma estética, em muitos aspectos diferente daquela produzida nas obras consagradas pela cultura das elites, e há, sobretudo, um universo de valores a ser conhecido, ainda mais num país com a diversidade cultural do Brasil. Todos esses aspectos - a reflexão, a estética e o universo de valores - indicam uma fala que deve ser não só "respeitada", mas conhecida, compreendida e confrontada - não nos esqueçamos da palavra como arena de lutas dos valores sociais.

Em relação aos LD, parece haver um consenso, entre pesquisadores e alguns documentos oficiais, sobre como não priorizam o ensino de literatura seja porque priorizam outros gêneros em detrimento dos literários (RANGEL, 2005; BELINTANE, 2011), seja porque abordam o texto literário de uma perspectiva mais tradicional (ZILBERMAN, 2009 e 2009a, PAULINO e COSSON, 2009, BRASIL, 2006 e 2012), o que evidentemente pouco contribui para a formação do leitor literário. 
Para Belintane, há uma clara preocupação com a diversidade de gêneros, como orientam os PCN, e os "gêneros úteis" - textos da esfera jornalística, textos instrucionais, publicidades - aparecem com maior frequência do que os literários. Outra semelhança é o tratamento superficial dado ao conhecimento das variações regionais - linguísticas e culturais. Para Belintane, essa estratégia está a serviço de interesses que preferem deixar de lado as singularidades culturais do país:

\footnotetext{
Talvez até seja por isso que apostar no texto instrucional, na receita, na propaganda, seja interessante para as editoras e para os autores, pois assim é possível contemplar o 'uso da língua' de uma forma mais generalizada, sem ter que fazer concessão à regionalidade - afinal, um universo de letramento sem singularidades não precisa ter cuidados sutis com as regionalidades, bastando apresentar aqui e ali alguns exemplos de "respeito à língua popular", para assim contemplar mais um item desses compromissos: a variação regional. (2011, p. 142)
}

Essa estratégia contribui, ainda, para evitaroutrotipodesingularidade, que acaba por não ser contemplada quando os textos literários não são tratados, ou são "maltratados" no ensino, trata-se das "singularidades da infância”. Para Belintane, os textos úteis estão carregados de uma "discursividadeadultocêntrica" (2011, p. 105) que dispensa a fantasia, a parte lúdica da linguagem, em favor de uma abordagem pragmática, voltada para um ensino que está a serviço de valores mais conectados a interesses mercadológicos do que propriamente a interesses pedagógicos. Assim, não deixa de haver certa coerência, pelo menos pela ótica do mercado, em metodologias de ensino que se esquivam de trabalhar com diferentes tipos de singularidades. Ao não se privilegiar a literatura, com seus longos textos que não são necessariamente "úteis", evita-se a trabalhosa entrada no universo das singularidades da infância, que exige conhecimentos de outra ordem por parte dos professores, educadores em diferentes funções, autores de livros didáticos. Sobre isso, falaremos mais adiante.

Estendendo sua crítica à avaliação oficial dos livros didáticos, feita por professores e pesquisadores das universidades brasileiras para o Ministério da Educação (MEC), Belintane conclui que há um "estranho comprometimento dos avaliadores com o neoliberalismo, com o mercado e, ainda, a adoção dessa postura afrouxada que permite essa substituição dos textos da boa literatura por textos bem triviais" (2011, p. 117). Em relação a esse procedimento, Rangel observa que "Na maioria dos guias curriculares, assim como em quase todos os LDP desse nível, a literatura é uma referência remota, presente apenas indiretamente na cena didática" (2005, p. 149). De alguma forma, o Guia de livros didáticos: PNLD 2013 confirma a crítica dos autores, na medida em que admite o tratamento superficial dado pelos LD aos textos literários de um modo geral: 
As coleções ainda são tímidas na proposição de apreciações estéticas, éticas, políticas, ideológicas, limitando-se, praticamente, a questões do tipo "Você gosta ou não gosta”. Também a exploração lúdica do texto é bastante reduzida, contribuindo-se pouco para fruição estética e para a apreciação crítica da produção literária pelo aluno. Embora venham situados no contexto histórico em que se inserem, os textos literários são pouco explorados na relação com o contexto de produção. (2012, P. 20)

Zilberman chega mesmo a radicalizar a crítica ao dizer que o LD "transcendeu o âmbito da sala de aula e converteu-se em uma vigorosa fonte de renda para autores, editores e livreiros" (2009b, p. 34).

\section{OS DESCOMPASSOS E SUAS POSSÍVEIS ORIGENS}

Se na vertente crítica em relação ao ensino de literatura há hoje um consenso sobre a necessidade de se reverter esse descompasso entre documentos e práticas institucionais, uma pergunta, que talvez venha contribuir para esclarecer esse quadro, refere-se a quais seriam os processos educacionais, sociais e culturais que sustentaram e sustentam essa desconformidade até aqui.

Em relação à metodologia de ensino de português, de um modo geral, Rangel (2005) dá uma boa pista para entendermos como determinados objetivos do ensino de língua não são os mesmos do ensino de literatura, e aí pode residir um nó importante da questão. O autor chama de "virada pragmática" as mudanças no ensino de língua desdea década de 80, quando a abordagem linguística passou a pautar as orientações metodológicas oficiais. Um dos objetivos básicos desse ensino é tornar o aluno proficiente no uso da língua oral e escrita. Rangel afirma que se essa qualidade é boa para formar um aluno que diante do texto "tem objetivos definidos e sabe avaliar, em cada situação de leitura, se dispõe de tempo e dos recursos necessários para atingi-los", sabe ainda reconhecer os gêneros, fazer previsões e interpretações, identificar o tema, reconhecer vozes etc. (2005, p. 152), não é a mais apropriada para orientar a formação do leitor literário, que não lê para, dado que o texto literário "abre uma perspectiva única de leitura" (p. 153). Na verdade, a leitura literária não "serve" a nenhum objetivo que não seja a leitura em si, sua polissemia intrínseca pede um leitor atento, nada mais, às vezes nem isso, podendo mesmo a experiência de leitura ser "vaga" - ao leitor, na literatura, é permitido flanar com a atenção solta de alguém que vai encontrando surpresas a cada página, ou não! Nada mais contrário, portanto, à noção de "proficiência no uso da língua”, com toda a sua carga pragmática, necessária, sem dúvida, para inúmeros procedimentos de leitura e escrita, mas inadequada quando se trata de trabalhar com a formação do leitor literário. 
Atento à questão, o MEC, além de estabelecer políticas concretas de formação de leitores por meio de programas como o Programa Nacional de Biblioteca na Escola (PNBE), dentre outros, vem produzindo um conjunto de documentos para discutir com estados e municípios o "papel da escola no desenvolvimento da competência leitora dos alunos". Ao comentar o resultado da Avaliação Diagnóstica do Programa Nacional Biblioteca da Escola, ${ }^{1}$ realizada pelo MEC/SEB em 2005, um desses documentos, Por uma política de formação de leitores (BERENBLUM e PAIVA, 2006), é bastante eloquente sobre as práticas pedagógicas em relação à leitura literária encontradas nas escolas brasileiras:

\begin{abstract}
A pesquisa revelou que a ausência de uma política de formação de leitores e de esclarecimentos suficientes aos professores sobre a utilização de acervos literários do PNBE em sua prática pedagógica gerou uma não-diferenciação das especificidades do livro didático, paradidático, obra de referência e livro de literatura. A lógica - que se percebeu - de tratamento das obras literárias, por exemplo, deixou de valorizar o lúdico, a fantasia, a imaginação, para enformar a fruição do gênero literário nos moldes escolares. Nesse aspecto, cabe destacar que, embora a literatura para as faixas etárias correspondentes ao Ensino Fundamental dirija-se a crianças, adolescentes e jovens - categorias que definem gostos, interesses, escolhas, sonhos, modos de perceber a realidade e com ela interagir, mediados por construções simbólicas e próprias da imaginação - na prática escolar essas marcas se apagam. Resta, apenas, a categoria aluno, que mantém suposta homogeneidade entre os sujeitos, sem respeitar a riqueza das experiências que vivenciam e ressignificam, mediadas pelos textos literários. P. 2
\end{abstract}

Se quisermos aprofundar a questão das práticas pedagógicas que não diferenciam o tratamento de textos literários de outros gêneros, pode-se afirmar que o problema parece se agravar quando se observa, em alguns casos, um tratamento metodológico distante de uma abordagem discursiva não só dos poucos textos literários que entram na sala de aula, mas também de outros gêneros. No caso do EF, por mais que as orientações metodológicas dos PCN sejam seguidas - basicamente o estudo da linguagem com uma abordagem linguístico-discursiva - algumas pesquisas (ROJO, 2006; BELINTANE, 2011) vêm comprovando nos últimos anos que a "distância entre intenção e gesto" ainda é uma realidade.

${ }^{1}$ Para subsidiar a elaboração de uma política de formação de leitores, que não se limitasse à aquisição e distribuição de livros para as escolas públicas, a Secretaria de Educação Básica (SEB) realizou, em 2005, seminários regionais, onde foram discutidas as ideias e conceitos que norteariam essa política. Nesse momento, foi realizada uma pesquisa para saber sobre o impacto da distribuição dos acervos do PNBE nas práticas de incentivo à leitura desenvolvidas nas escolas brasileiras. 
O "gesto" pode ser observado, por exemplo, nos dados obtidos por pesquisa colaborativa de formação de professores, feita entre 1999-2001 numa escola de Ensino Fundamental I e II na cidade de São Paulo para investigar, dentre outros aspectos, os processos discursivos, mais próprios de gêneros secundários, presentes em aulas de diversas disciplinas Ciências, Matemática, História, Geografia, além de Língua Portuguesa (ROJO, 2006). Dentre as constatações feitas, observa-se que: ler e escrever textos eram atividades pouco frequentes - "Tudo se passa como se a escrita de textos estivesse reservada para a aprendizagem dos princípios alfabéticos e ortográficos e das regras do bem escrever" (ROJO, 2006, p. 68) -; as discussões argumentativas eram raras, raras também eram as atividades de leitura e escrita, não restritas à resolução de exercícios ou à resposta pontual a questionários, que tomavam como objeto de estudo gêneros secundários como relatos históricos, poemas, letras de canção, fotos, mapas, contos, anúncios, listas, crônicas, fragmentos de romances, dentre outros.

Como conclusão da análise dos dados da pesquisa, Rojo observa que não houve inter-relação entre a voz do aluno, do professor e dos discursos presentes nos gêneros vistos em aula: "Ao contrário, o que vimos em grande parte da amostra analisada é um estilo autoritário de condução do discurso por parte do professor, que exige reconhecimento e repetição automática dos alunos” (2006, p.71). Rojo chama esse processo de ventriloquismo: atitude típica de uma educação autoritária que impõe, tanto ao aluno quanto ao professor, a repetição automática das vozes consagradas pelas instituições por intermédio, sobretudo, dos textos didáticos.

Além da questão de que o tratamento dado aos gêneros de outras esferas está bem distante da abordagem discursiva nas salas de aula estudadas na pesquisa de Rojo - tratamento provavelmente representativo do que acontece em certas esferas do ensino brasileiro -, há também a tentativa, em algumas avaliações oficiais e LD, de se esquivar do tratamento teórico adequado com abordagens metodológicas que seguem as orientações dos PCN apenas em parte. Por exemplo, em algumas provas avaliativas, nas questões voltadas para análise de propaganda, Belintane (2011) observa como, de um modo geral, o tratamento parece estar plenamente adequado às atuais teorias da linguagem: considera-se a diversidade de gêneros, a propaganda faz parte do universo do letramento do aluno etc. No entanto, não há uma abordagem crítica desse tipo de texto, isto é, evita-se situá-lo em seu contexto histórico e, portanto, em sua finalidade mais óbvia: textos publicitários são feitos para vender produtos. A abordagem permanece 
num nível superficial, no mais das vezes, cuja finalidade resume-se a aferição de habilidades básicas. ${ }^{2}$

Independentemente do gênero, numa perspectiva discursiva, a linguagem não é neutra, como se sabe; há, em qualquer discurso, um posicionamento ideológico da enunciação demarcando seu lugar na arena de luta da palavra (BAKHTIN, 1988). Numa abordagem de texto, quando se deixa de pontuar essa relação, dialógica e, portanto, valorativa, não há abordagem discursiva. Pode ser, no melhor dos casos, uma abordagem linguístico-discursiva como aquela proposta pela equipe da Universidade de Genebra, cuja produção teórica foi bastante estudada nos últimos anos em determinados nichos das universidades brasileiras3. Para essa concepção de ensino de língua, "a ênfase maior é dada às capacidades linguístico-discursivas ligadas às formas composicionais ou ao estilo", já a " busca do sentido ou do efeito de sentido não é seu norte (nem seu forte) principal” (ROJO, 2006, p. 74). Em suma, para uma abordagem discursiva do tratamento dos gêneros, a orientação volta-se para uma interpretação do texto que permita, ao professor e ao aluno, estabelecer uma autêntica relação dialógica com os diferentes discursos.

E aqui provavelmente entramos em terreno ainda mais complicado. $\mathrm{O}$ consenso da vertente crítica transcende a questão do ensino de literatura e se amplia até o ensino em um sentido geral. A crítica a uma educação engessada em parâmetros restritos à reprodução de modelos recebe vários nomes além de "ventriloquismo": "mal da escolarização" (BERENBLUM e PAIVA, 20o6) "letramento serviçal" (PAULINO e COSSON, 2009), "pedagogia da facilitação" (OSAKABE, 2005). Em todas essas definições, a crítica é sustentada pela noção de que o aluno não é formado para construir sua voz, individual e social de modo crítico e criativo, mas para reproduzir as vozes das instituições, de modo autoritário e submisso.

2 Há casos mais comprometedores ainda, quando, por exemplo, um texto de publicidade vem inserido numa atividade como se fosse um mero texto instrucional. É o caso de uma questão da Prova da Cidade, citada por Belintane (2011, p. 124), em que há instruções para desenhar uma boneca da marca X, e que se limita a aferir a habilidade de ordenar informações. A propaganda está explícita no teste e, no entanto, pede-se ao aluno tratá-la como se fosse um texto de outro tipo. Nesse caso, é difícil distinguir o que é má fé do que é somente uma abordagem mal feita.

3 Um dos livros mais conhecidos dessa equipe, editado no Brasil, é Gêneros orais e escritos na escola, de Bernard Schneuwly et al. Tradução e organização de Roxane Rojo e Glaís Sales Cordeiro. Campinas, Mercado de Letras, 2004. 
Para tentar entender, de uma perspectiva social e cultural, o que acontece nesse processo, que vai desde a crítica específica a determinados aspectos do ensino de literatura e passa pelo ensino de modo geral, propomos recordar o clássico ensaio "O narrador", escrito em 1936, por Walter Benjamin. Ali, o filósofo frankfurtiano já anunciava a estreita relação entre as condições materiais responsáveis pela expansão da informação e o efeito direto desse processo que levou à crise da experiência objetivada na crise da narração. Para o autor, a arte de narrar permite "a faculdade de intercambiar experiências" (1986, p. 198) ao contrário da relação com a circulação abstrata da informação que já estabelece, a priori, explicações para tudo. Com isso, perde-se a possibilidade de viver os efeitos de "histórias surpreendentes", e, por consequência, ao longo do tempo, até mesmo de senti-los e/ou identificá-los. Na relação entre o narrador e o ouvinte, Benjamin diz que a imaginação é chamada não a responder perguntas objetivas e pontuais, mas a criar possibilidades de continuidade diferentes para as narrativas. A imaginação é chamada a criar, a estabelecer relações por intermédio de inter-relações com o narrador, com as histórias, com o outro: "Quanto mais profundamente o ouvinte se esquece de si mesmo, mais profundamente se grava nele o que é ouvido". (BENJAMIN, 1986, p. 205).

Benjamin desvendou uma crise própria do século XX, pós-invenções dos meios de comunicação de massa, cuja marca se pulverizaria de modo indelével na experiência da cultura ocidental. Por essa abordagem, podese compreender como a tendência a uma formação educativa calcada em um viés pragmático veio tomando corpo de modo a compactuar, sem conflitos, com a versão pós-moderna do capitalismo, o neoliberalismo. Da forma como se estabeleceram as relações nesse sistema, não se prioriza a troca de experiências, no sentido benjaminiano - "o lado épico da verdade" que só pode ser transmitido pela experiência do outro -, mas a troca de informação, a circulação de dados, que permite a rapidez, a fluidez, das relações econômicas e, por conseguinte, das relações sociais. Isso significa, como se sabe, que as necessidades do mercado estão acima de quaisquer outros interesses - atualmente, defende-se o direito ao lucro como um mantra sacrossanto intocável e, sobretudo, inquestionável. Enfim, em seu princípio criador, nada mais distante do universo mercadológico do que a arte, seja ela de que origem for. Deleuze chega mesmo a prever o fim da boa literatura no limite desse processo:

Os anunciantes são os verdadeiros clientes, eu dizia, na edição há um risco de que os verdadeiros clientes dos editores não sejam os leitores em potencial, que sejam os distribuidores, quando eles forem, realmente, os clientes dos editores, 
o que acontecerá? O que interessa aos distribuidores é a rotação rápida, quer dizer, coisas de grandes mercados de rápida rotação, regime do best-seller, etc.; ou seja, que toda a literatura, se ouso dizer, à la Beckett, toda a literatura criadora será esmagada por natureza. (1988, p. 16)

Não é possível, por várias razões, para a literatura dobrar-se - tanto no nível da produção quanto da recepção - ao universo da rotação rápida dos mercados, e também por isso, por exigir outro tempo de maturação de seus leitores, ela pede que a formação pedagógica a divulgue e a trate de acordo com critérios que apostem na necessidade de sua permanência na experiência humana para todas as pessoas. Além disso, uma boa educação literária - que, no fim das contas, significa fomentar o hábito da leitura de textos literários, independente de metodologias ${ }^{4}$ - acaba por contribuir para uma formação dialógica: ao leitor acostumado à literatura não lhe bastam informações que "tudo explicam", tampouco estabelece facilmente uma interlocução passiva, pois sua maturidade leitora quase que o obriga a manter uma relação reflexiva com os textos.

\section{UM PASSO PARA O COMPASSO:A ABORDAGEM PSICANALÍTICA}

Muito dos artigos que denunciam o apagamento da literatura no ensino brasileiro, justificam-no sob diferentes perspectivas: Osakabe (2005), prioritariamente pela filosófica, Zilberman (2009 e 2009a) e Fischer et al. (2012), pela histórica e sociológica, Rangel (2005) Paulino e Cosson (2009), pela linguístico-discursiva. Propomos uma abordagem psicanalítica, própria de outros campos acadêmicos, porque pode vir a ser uma soma importante nesse rol de perspectivas na defesa de um ensino de literatura, cujo principal objetivo seja a formação do leitor literário.

Pode-se argumentar "em favor" de uma educação literária desde uma perspectiva pragmática, dado que o hábito de ler textos literários contribui para a formação de um sujeito "mais hábil no uso da língua" capaz de ter "uma inteligência mais sutil, mais crítica", até uma abordagem ampla, estética e eticamente falando, porque leva em consideração a formação de um sujeito "mais capaz de explorar a experiência humana, atribuindolhe sentido e valor poéticos" (PETIT, 2012, p. 29). Entretanto, no limite, talvez a experiência de leitura de textos literários possa significar algo mais, além de ganhos pragmáticos, estéticos e éticos na formação de um modo geral.

${ }_{4}^{4}$ Como atestam depoimentos de escritores famosos - Manuel Bandeira, Cyro dos Anjos e Paulo Mendes Campos - citados por Zilberman (2009, pp 12-14). 
Em $A$ arte de ler ou como resistir à adversidade (2012), Michele Petit comenta diversas experiências de leitura de textos literários com grupos em contexto de crise ${ }^{5}$ que permitiram contribuições transformadoras para o desenvolvimento psíquico de seus participantes. A autora descreve um tipo de abordagem, próprio para intervenções em contextos críticos: as situações devem permitir encontros "gratificantes de subjetividade", o que significa que os participantes podem falar à vontade sobre suas impressões e experiências "assim as leituras abrem para tempos de devaneio que permitem a construção de um mundo interior, um espaço psíquico" (2012, p. 32-33). Esse espaço permite elaborar a reconstrução de uma narrativa sobre a experiência traumática vivida, torna possível um discurso sobre os dramas, as dores, as perdas das pessoas que passaram por situações difíceis.

Observa-se nessa abordagem exatamente aquele processo descrito por Benjamim: por meio da narrativa literária, o ouvinte/leitor estabelece vínculos subjetivos entre o texto e sua própria história, que pode deixar, assim, de ser vista/sentida como única - muitas vezes percebida como indizível, não simbolizada - e passa a fazer parte de um todo maior, de uma história mais ampla, onde há outras personagens envolvidas, muitas vezes, com as mesmas dores, com trajetórias semelhantes: "Quanto mais profundamente o ouvinte se esquece de si mesmo, mais profundamente se grava nele o que é ouvido". (BENJAMIN, 1986, p. 205). A experiência individual pode ser ampliada em uma experiência coletiva por intermédio do texto literário e, evidentemente, das trocas de experiências e impressões possibilitadas por esses grupos. A elaboração estética do texto literário, da narrativa, sobretudo, permitiria uma espécie de tranquilidade, pois "o tempo é ordenado, os acontecimentos contingentes ganham sentido em uma história vista em perspectiva” (PETIT, 2012, p. 224). A elaboração estética permite, abre espaço, para a elaboração psíquica.

Assim, o que Petit apresenta é um tipo de experiência, possibilitada pelo texto literário (por textos artísticos de modo geral), que permite uma ressignificação da história de pessoas que passaram/passam por sérios momentos de crise: ao poderem reorganizar a própria história, têm a possibilidade de transformá-la de um modo transgressor, em um sentido mais amplo porque profundamente político "transgressão que consiste

5 Para Petit, esses grupos têm ou tiveram experiências traumáticas de separação de pessoas próximas, perda da casa ou da paisagem familiar: "Uma crise se estabelece de fato quando transformações de caráter brutal - mesmo se preparadas há tempos -, ou ainda uma violência permanente e generalizada, tornam extensamente inoperantes os modos de regulamentação, sociais e psíquicos, que até então estavam sendo praticados” (2012, p. 20). 
em deixar as imposições sociais e se apropriar dos lugares e dos objetos que não eram destinados a eles" (2012, p. 42).

Mas será que esse processo, de ressignificação da história subjetiva por meio da literatura, só faz sentido em contextos de crise? Será que o mesmo procedimento não poderia contribuir para a construção de uma subjetividade capaz de sustentar uma posição criativa, transformadora eao mesmo tempo crítica do sujeito, independente de contextos específicos? O livro de Maíra Soares Ferreira, A rima na escola, o verso na história (2012), responde afirmativamente a essa pergunta. Trata-se de seu mestrado (Faculdade de Educação/USP), na forma de um estudo-intervenção com jovens, entre 13 e 14 anos, alunos de uma escola municipal situada próximo a uma favela paulistana -, que procurou "avaliar as possibilidades de um exercício de afirmação étnico-social do passado (re) negado no ambiente escolar e social desses jovens" (FERREIRA, 2012, P. 167).

Logo no início da pesquisa, Ferreira registrou que a comunidade dessa favela é proveniente do sertão de Pernambuco: boa parcela afro-brasileira e indígena descendente dos índios Pankararu. Concomitantemente, a autora percebeu que não havia na escola, de um modo geral, "o (re) conhecimento histórico e cultural daquela comunidade, experiência fundante e propiciadora da singularidade do sujeito" (2012, p. 24), o que foi corroborado pela produção poética inicial (criação de rap) dos jovens, em que havia certa negação da história daquela comunidade mascarando questões sociais e políticas e, ao mesmo tempo, indicando um universo marcado pelo preconceito e pela discriminação de várias ordens. A partir dessa produção, seu estudo introduziu um diálogo com as produções poéticas nordestinas - cordel, repentes (cantoria de viola e coco de embolada), partindo da hipótese de que "o jovem, pelo contato com as culturas de seus antepassados, poderia apropriar-se de seu passado e, com isso, ter mais condições para (re) contar e (re) criar sua história sem se render ao preconceito a que se encontra submetido" (FERREIRA, 2012, p. 27). Num primeiro momento, os jovens não se identificaram com a cultura nordestina, mas no rap e no hip-hop havia o conteúdo eloquente de toda a "história de diáspora, aldeamentos e hibridismos" de seus familiares provenientes do sertão nordestino (FERREIRA, 2012, p. 165) atravessado pelo sofrimento "atualizado" da exclusão na cidade de São Paulo.

E o que antes de iniciar seu estudo-intervenção era distante - a cultura nordestina - ou negado - o preconceito e a discriminação - com o atravessamento das manifestações culturais juvenis - o rap, o hip-hop - passou a fazer sentido, passou a ser compreendido como uma parte importante da história de cada um daqueles jovens, de suas famílias e de seus antepassados. Ferreira percebeu a história e a estória entrelaçadas: 
"Muitas apropriações e recombinações culturais revelam a contínua marcha da criatividade do sujeito - condição essencial para uma vida em transformação. (...) aqueles jovens afro-indígenas paulistanos são herdeiros de um processo sociocultural nordestino que envolve desde a violência e a segregação das diásporas até a criação poética e musical presentes tanto nas histórias de improviso do sertão quanto nas expressões juvenis e urbanas da sala de aula da metrópole paulistana.” (2012, p. 26)

De certa forma, a tese de Belintane corrobora o princípio de que a história subjetiva pode ser ressignificada, de modo criativo, por intermédio da literatura, quando propõe que a oralidade (o trabalho didático com textos provenientes da tradição oral) deve ser a base para o processo de alfabetização. Belintane analisa de uma perspectiva psicanalítica o jogo lúdico implícito nos gêneros da tradição oral - parlendas, cantigas de roda, fórmulas de escolha, adivinhas, enigmas, trava-línguas, narrativas orais populares, dentre outros - e vê nesse processo uma economia de gozo; a criança investe sua energia "em seus personagens, assumindo uma outra corporalidade, mais simbólica, mais independente do hardware corporal, que tem condições de acompanhar as aventuras dos personagens" (2011, p. 187). Também nessa proposta, portanto, há uma interpretação que compreende a vivência com textos literários como parte importante para o desenvolvimento psíquico: “(...) quando a criança bordeja o nonsense, abrindo a linguagem ao mistério, ao estranhamento, está também revitalizando seu psiquismo, suas possibilidades de releitura, tanto da vida como da palavra." (BELINTANE, 2011, p. 154).

A relação entre o jogo - o brincar - e a literatura - como produto de um tipo de "devaneio" - é bem conhecida da psicanálise desde o ensaio "Escritores criativos e devaneio", de Freud. Sua hipótese é a de que há um tipo de investimento psíquico feito tanto pela criança, no ato de brincar, quanto pelo escritor, no ato de criar: há uma enorme quantidade de emoção investida no "mundo da fantasia" e, ao mesmo tempo, há discernimento entre o que é ficção e o que é realidade, em ambos os atos. Isto é, o jogo é visto "como processo de criação para a subjetividade" (BIRMAN, 2002, p.128). Para Freud, "A linguagem preservou essa relação entre o brincar infantil e a criação poética", há um tipo de prazer proveniente de "uma libertação de tensões em nossas mentes. Talvezatégrande parte desseefeito seja devido à possibilidade que o escritor nos oferece de, dali em diante, nos deleitarmos com nossos próprios devaneios, sem autoacusações ou vergonha" (1988).

Ao comentar a tese freudiana a respeito da relação entre jogo e literatura, Birman afirma que essa é uma das formas que a subjetividade tem para lidar "com a conflitualidade que necessariamente a atravessa de 
fio a pavio, transformando-a em experiência de satisfação e em realização dedesejo." (BIRMAN, 2002, p. 128). Para realizar a experiência de satisfação, o eu tem de entrar numa espécie de "devaneio", em que experimenta sua "reinvenção ficcional", com múltiplos personagens que entram em cena e tomam seu lugar:

"Novas ficções sobre o mundo e outros roteiros de percursos na existência são assim inventados e colocados em cena, suspendendo o juízo de existência do jogador/sonhador com vistas a engendrar outra subjetividade possível, pela criação de novas marcas psíquicas e objetos outros de satisfação." (BIRMAN, 2002, p. 128).

Para Birman, esse processo estabelece uma marca ficcional próxima do jogo - inclusive no próprio pensamento, que está a todo momento "articulando os possíveis hipotéticos a partir da virtualidade e do imponderável” (2002, p. 129). Assim, da mesma forma que no ato de brincar e no de criar, há uma reinvenção contínua, como parte intrínseca ao processo, também haveria no ato de pensar muito dessa criatividade própria do jogo "uma vez que pensar seria jogar com outros possíveis, reinventando novos enunciados sobre si próprio e sobre o mundo". (BIRMAN, 2002, p. 129).

Pode-se observar, com base nas considerações feitas até aqui, como a abordagem psicanalítica contribui para estabelecer a importância da literatura na formação escolar para além das razões pragmáticas, éticas e estéticas. A possibilidade de ressignificar o passado soma-se à transformação do presente em muitos casos, sobretudo, quando o sujeito pode experimentar os "múltiplos personagens", as múltiplas vozes da ficção exterior e interior, e se apropriar de sua história. Esse processo descreve uma das chaves para a compreensão da importância da formação literária: nessa articulação entre a reinvenção de si e do mundo pode haver um amadurecimento psíquico que implique um gesto político, na medida em que, como demonstram os estudos de Petit (2012) e Ferreira (2012), em vários casos, as pessoas se apropriaram de suas próprias vozes, e de sua história consequentemente, de um modo, muitas vezes, transformador não só de sua visão de mundo, mas de sua condição.

Aqui se encontra uma pista para compreender, pelo menos em parte, o descompasso entre os documentos oficiais e certas práticas que "burlam" as orientações para mascarar um enfoque discursivo do ensino, ou até mesmo defendem os interesses do mercado editorial: "formar um sujeito autônomo e crítico" é um objetivo vazio de sentido nessas práticas. Como vimos, o que se exige do aluno - em determinados livros didáticos, algumas avaliações oficiais, e em muitas aulas - éa mera repetição de vozes consagradas pela "autoridade". E a vivência de textos literários contribui 
diretamente para formar um aluno que não se limita à repetição passiva das vozes consagradas; há um tipo de transgressão implícito no próprio processo de formação: "não é somente um reconhecimento de si que a literatura permite, mas uma mudança de ponto de vista, um encontro com a alteridade e talvez uma educação dos sentimentos" (PETIT, 2012, p. 110).

A transgressão mais profunda, talvez, refira-se à possibilidade de, por meio de um mergulho na subjetividade - o "devaneio" que a literatura permite -, chegar-se ao outro por uma interlocução mais fina e inteligente, porque consciente de que a condição humana é universal. A linguagem artística pode contribuir diretamente para o esclarecimento quando acontece a interlocução, mesmo nas condições mais difíceis. $\mathrm{O}$ cantor e compositor Criolo, oriundo da periferia paulistana, sintetiza bem essa relação: "Crescemos entre mazelas, mas o pouco de arte que nos davam, um grafite que a gente via, uma música que alguém mostrava, isso ajudava a abrir nossos olhos para algo maior, embora não acabasse com o sofrimento." (2012). Essa educação sentimental, própria da experiência artística, é acompanhada não só da desilusão, mas também de um tipo de esclarecimento capaz de projetar positividades.

O artista cita a música como fonte importante para a reflexão; na cultura brasileira, esse é um dos universos mais expressivos de manifestação. Não por acaso, ao defender uma didática da língua materna prioritariamente discursiva, Rojo propõe uma ponte entre o estudo da música e a literatura: “(...) nós brasileiros temos uma grande fortuna: a de termos nascido num país musical. Não parece, no Brasil, ser tão difícil iniciar nas artes por meio da música (e da imagem), aproximar a literatura valorizada de gêneros da tradição oral e popular." (2006, p. p.74).

Há uma contribuição inegável da literatura para um amadurecimento psíquico, político, linguístico e cultural daqueles que têm acesso aos textos dessa esfera. Quando a literatura entra na escola, portanto, e é parte importante do currículo tem-se a chance de se formar pessoas que estabelecem relações com os diversos discursos de modos diferentes, com o que poderíamos chamar de "criatividade crítica", em que sua voz é parte do conhecimento que está sendo produzido na instituição. O aluno, cuja formação passa seriamente pela leitura frequente de textos literários (artísticos em geral), não se limita a detectar informações para repassá-las de modo "eficiente" (rápido, produtivo); pode compreender as metáforas, o não dito, os desafios das tantas perguntas geradas ao longo do processo de ensino-aprendizagem e que permanecem, às vezes, uma vida toda sem respostas. Desse modo, compreende-se por que o estudo da literatura é importante de uma perspectiva analítica, discursiva, política e não mercadológica. 


\section{Pinto - 475 \\ REFERÊNCIAS BIBLIOGRÁFICAS}

BAKHTIN, Mikhail. Marxismo e filosofia da linguagem. Tradução de Michel Lahud e Yara Frateschi Vieira com a colaboração de Lúcia Teixeira Wisnik e Carlos Henrique D. Chagas Cruz. 4. ed. São Paulo: Hucitec, 1988.

BELINTANE, Claudemir. A oralidade faz escrita na(s) infâncias(s): pesquisas e reflexões sobre a relação oralidade - escrita nos anos iniciais de escolarização. Tese (Livre Docência) - Faculdade de Educação/USP, 2011.

BENJAMIN, Walter. O narrador. Considerações sobre a Obra de Nikolai Leskov. Tradução de Sergio Paulo Rouanet. In: Magia e técnica, arte e política. 2. ed. São Paulo: Brasiliense, 1986, pp. 197-221.

BERENBLUM, Andréa; PAIVA, Jane. Por uma política de formação de leitores. Brasília: Ministério da Educação, Secretaria de Educação Básica, 2006.

BIRMAN, Joel. Fantasiando sobre a sublime ação. In: Bartucci, G. Psicanálise, arte e estéticas da subjetivação. Rio de Janeiro: Imago, 2002, pp. 89-130.

BRASIL. Secretaria de Educação Fundamental. Parâmetros Curriculares Nacionais: Terceiro e Quarto Ciclo do Ensino Fundamental - Brasília. MEC/SEF, 1998.

BRASIL. Parâmetros Curriculares Nacionais: Ensino Médio. Brasília: MEC/Semtec, 2000.

BRASIL. PCN+ ensino médio: orientações educacionais complementares aos Parâmetros Curriculares Nacionais.Volume Linguagens, códigos e suas tecnologias. Brasília: MEC/SEMTEC, 2002.

BRASIL. Orientações curriculares do ensino médio. Linguagens, códigos e suas tecnologias / Secretaria de Educação Básica. - Brasília: Ministério da Educação, Secretaria de Educação Básica, 2006.

BRASIL. Ministério da Educação, Secretaria de Educação Básica. Guia de livros didáticos: PNLD 2013: letramento e alfabetização e língua portuguesa. - Brasília: 2012. 256 p.

CRIOLO. Entrevista disponível em http://www1.folha.uol.com.br/ilustrada/1150334emicida-e-criolo-gravam-primeiro-dvd.shtml. Acesso em 24.10.2012.

DELEUZE, Gilles. O Abecedário de Gilles Deleuze. Transcrição integral do vídeo, 1988. Disponível em: http://www.ufrgs.br/corpoarteclinica/obra/abc.prn.pdf. Acesso em 19 de outubro de 2012.

FERREIRA, Maíra Soares. A rima na escola, o verso na história. São Paulo: Boitempo Editorial, 2012.

FISCHER, Luís Augusto; LUFT, Gabriela; FRIZON, Marcelo; LEITE, Guto; LUCENA, Karina; VIANNA, Carla; WELLER, Daniel. A Literatura no Exame Nacional do Ensino Médio (ENEM). Nonada Letras em Revista. PortoAlegre, ano 15, n. 18, p. 111-126, 2012. Disponível em < http://seer.uniritter.edu.br/index.php/nonada/article/viewFile/531/315>. Acesso em 11 de julho de 2013. 
FREUD, Sigmund. Escritores criativos e devaneios. In: Edição Eletrônica de Freud. Texto integral da Edição Standart Brasileira das Obras Psicológicas Completas de Sigmund Freud. Vol. IX. Tradução de Maria Aparecida Moraes Rego. Rio de Janeiro: Imago, 1988.

OSAKABE, Haquira; FREDERICO, Enid Yatsuda. Literatura. Orientações curriculares do ensino médio. Brasília: MEC/ SEB/ DPPEM, 2004.

OSAKABE, Haquira; FREDERICO, Enid Yatsuda. Poesia e indiferença. In: Leituras literárias: discursos transitivos. Aparecida Paiva, Aracy Martins, Graça Paulino, Zélia Versiani (orgs.) Belo Horizonte: Ceale; Autêntica, 2005. P. 37-54.

PAULINO, Graça; COSSON, Rildo. Letramento literário: para viver a literatura dentro e fora da escola. In: RÖSING, Tânia M.K; ZILBERNAM, Regina (orgs.). Escola e leitura: velha crise, novas alternativas. São Paulo: Global, 2009. 61-79.

PETIT, Michèle. A arte de ler ou como resistir à adversidade. Tradução de Arthur Bueno e Camila Boldrini. 2 ed. São Paulo: Editora 34, 2012.

RANGEL , Egon de Oliveira. Literatura e livro didático no ensino médio: caminhos e ciladas na formação do leitor. In: Leituras literárias: discursos transitivos. Aparecida Paiva, Aracy Martins, Graça Paulino, Zélia Versiani (orgs.) Belo Horizonte: Ceale; Autêntica, 2005. P. 143-162.

ROJO, Roxane. O texto como unidade e o gênero como objeto de ensino de Língua Portuguesa. In: L. C. Tavaglia (Org.) Encontro na linguagem - Estudos lingüísticos e literários. Uberlândia, MG: EDUFU, 2006, pp. 51-80.

VOLOCHÍNOV, Valentin N. A construção da enunciação e outros ensaios. Organização, tradução e notas de João Wanderley Geraldi. São Carlos, Pedro \& João Editores, 2013.

ZILBERMAN, Regina. Que literatura para a escola? Que escola para a literatura? Revista do Programa de Pós-Graduação em Letras da Universidade de Passo Fundo - v. 5 - n. 1-9-20 - jan./jun. 2009.

ZILBERMAN, Regina. A escola e a leitura da literatura. In: RÖSING, Tânia M.K; ZILBERNAM, Regina (orgs.). Escola e leitura: velha crise, novas alternativas. São Paulo: Global, 2009a. P. 17-39. 